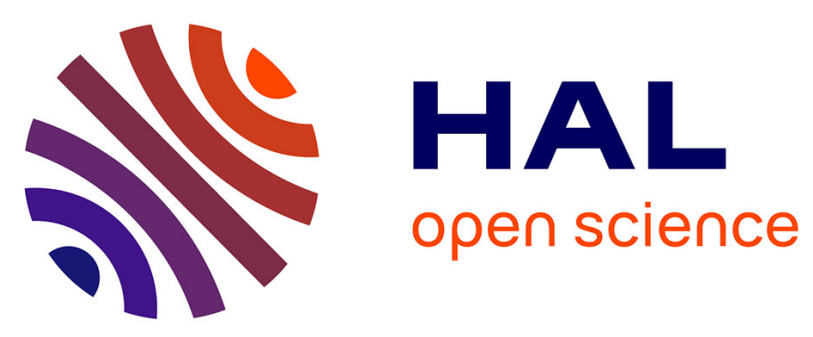

\title{
Prevalence and reliability of phonological, surface, and mixed profiles in dyslexia: A review of studies conducted in languages varying in orthographic depth
}

Liliane Sprenger-Charolles, Linda S Siegel, Juan E. Jimenez, Johannes Ziegler

\section{- To cite this version:}

Liliane Sprenger-Charolles, Linda S Siegel, Juan E. Jimenez, Johannes Ziegler. Prevalence and reliability of phonological, surface, and mixed profiles in dyslexia: A review of studies conducted in languages varying in orthographic depth. Scientific Study of Reading, 2011, 15 (6), pp.498-521. hal-00733553

\author{
HAL Id: hal-00733553 \\ https://hal.science/hal-00733553
}

Submitted on 1 Oct 2012

HAL is a multi-disciplinary open access archive for the deposit and dissemination of scientific research documents, whether they are published or not. The documents may come from teaching and research institutions in France or abroad, or from public or private research centers.
L'archive ouverte pluridisciplinaire HAL, est destinée au dépôt et à la diffusion de documents scientifiques de niveau recherche, publiés ou non, émanant des établissements d'enseignement et de recherche français ou étrangers, des laboratoires publics ou privés. 
Liliane Sprenger-Charolles*, Linda S. Siegel**, Juan E. Jiménez *** and Johannes C. Ziegler****

Prevalence and Reliability of Phonological, Surface, and Mixed Profiles in Dyslexia: A Review of Studies Conducted in Languages Varying in Orthographic Depth

Scientific Studies of Reading (SSSR)

$2011,6,498-521$

Accepted for publication (05-Sep-2010)

Liliane Sprenger-Charolles*, CNRS (LPP-UMR-8158) and Paris Descartes, France Linda S. Siegel**, University of British Columbia, Vancouver, Canada Juan E. Jiménez $* * *$ University of La Laguna, Spain

Johannes Ziegler**** CNRS (LPC-UMR-6146) and Aix-Marseille University, France

Address for correspondence: Liliane Sprenger-Charolles

Laboratoire de Psychologie de la Perception, CNRS et Université Paris Descartes.

UFR Biomédicale des Saints Pères, 45, rue des Sts Pères, 75270 Paris cedex 06

Tel: 331428643 25, e.mail: Liliane.Sprenger-Charolles@ parisdescartes.fr 


\begin{abstract}
The influence of orthographic transparency on the prevalence of dyslexia subtypes was examined in a review of multiple-case studies conducted in languages differing in orthographic depth (English, French and Spanish). Cross-language differences are found in the proportion of dissociated profiles as a function of the dependent variables (speed or accuracy), the classification method (classical versus regression-based methods), and the control sample (chronological age versus reading level controls). The classical method results in a majority of mixed profiles, whereas the regression-based method results in a majority of dissociated profiles. However, the regression-based method appears to result in less reliable subtypes within and between languages. Finally, reading-level comparisons revealed that the phonological subtype reflects a deviant developmental trajectory across all languages, whereas the surface subtype corresponds to a delayed developmental trajectory. The results also indicate that reading speed should be considered to correctly classify dyslexics into subtypes, at least in transparent orthographies.
\end{abstract}

Key words: Developmental Dyslexia; Subtypes; Orthographic Depth; Phonological Dyslexia; Surface Dyslexia; Mixed Profile; Vocal response latency; 
One of the most influential models of reading is the dual-route model (Coltheart, Curtis, Atkins, \& Haller, 1993; Coltheart, Rastle, Perry, Langdon, \& Ziegler, 2001). Although the model was proposed to explain skilled reading and acquired dyslexia, it has had a significant impact on the field of developmental dyslexia (e.g., Bergmann \& Wimmer, 2008; Ziegler, Castel, Pech-Georgel, George, Alario, \& Perry, 2008), especially with regard to the question of whether there are subtypes of dyslexia (e.g. Castles \& Coltheart, 1993; Manis, Seidenberg, Doi, McBride-Chang \& Peterson; Sprenger-Charolles, Colé, Lacert, \& Serniclaes, 2000; Stanovich, Siegel \& Gottardo,1997).

According to the dual-route model, written words can be processed either by a lexical reading route (also called orthographic procedure) or a sublexical reading route (also called phonological procedure). The lexical route is typically assessed with the reading of highfrequency irregular word, whereas the sublexical route is typically assessed with the reading of pseudowords. Dyslexics are assumed to be phonological dyslexics when pseudoword reading is impaired but irregular word reading is spared; they are assumed to be surface dyslexics when irregular word reading is impaired but pseudoword reading is spared. A mixed profile is found when both pseudoword and irregular word reading are impaired.

The dual-route model has been developed in the context of the English language ${ }^{1}$. English has one of the most inconsistent alphabetic writing systems, in which the same spelling can be pronounced in many different ways, as in though, through, bough, tough and dough (e.g., Ziegler, Stone \& Jacobs, 1997). In orthographies with a high number of inconsistencies, it could be useful for a reading system to develop two independent routes, a lexical route for dealing with the inconsistencies (i.e., irregular words) and a sublexical route for reading novel and low-frequency words. Some researchers have questioned the extent to which these two routes develop in more transparent orthographies. For example, Ziegler and Goswami (2005) state: "Given that English seems to lie at the extreme end of the consistency continuum with regard to orthography-phonology relationships, it might even be the case that some of the most sophisticated processing architecture (e.g., two separate routes to pronunciation in the skilled reading system) may in fact only develop for English" (p. 19). Similarly, Share (2008) claimed that "the Coltheart/Baron dual-route model....arose largely in response to English spelling-sound obtuseness. The model accounts for a range of English-language findings, but is ill-equipped to serve the interests of a universal science of reading" (p. 584).

In addition, it is quite clear that these two routes do not develop independently. Indeed, according to longitudinal data, the sublexical reading route provides a bootstrapping mechanism for reading acquisition in all alphabetic writing systems (e.g. for reviews, Share, 1995; Sprenger-Charolles, Colé, \& Serniclaes, 2006; Ziegler \& Goswami, 2005). As a consequence, and given that the dyslexics' sublexical reading skills are generally impaired (Rack, Snowling, \& Olson, 1992; Siegel, 1993; Siegel, 1998; Siegel, 1999; SprengerCharolles et al., 2006; Stanovich \& Siegel, 1994; Ziegler, Perry, Ma-Wyatt, Ladner \& Schulte-Korne, 2003a), their lexical reading skills should be impaired as well. Therefore, the percentage of mixed profiles (with impaired lexical and sublexical reading skills) is assumed to be very high, and we should find only very little evidence for dissociated profiles (such as surface or phonological profiles) in developmental dyslexia in any alphabetic writing system, at least in the comparison with average readers of the same chronological age. This idea is also at the core of the connectionist models of reading, in which very severe phonological impairments should lead to a mixed profile (e.g., Harm \& Seidenberg, 1999; see also: Plaut, McClelland, Seidenberg, \& Patterson, 1996; Seidenberg \& McClelland, 1989). However, if there are dissociated profiles, one might predict that they differ across languages, especially phonological profiles because phonological decoding is easier to acquire in transparent than in opaque writing systems (Ziegler et al., 2010). 
Given the concerns about the universality of the dual-route architecture and its developmental plausibility, this review was designed to assess the prevalence of phonological, surface and mixed profiles in developmental dyslexia across three languages that lie on a transparency continuum from English (very opaque) to French (intermediate) to Spanish (transparent). Indeed, grapheme-phoneme mappings are less consistent in English than in French and less consistent in French than in Spanish (for descriptive and/or quantitative indicators of the consistency of these orthographies, see: Borgwaldt, Hellwig, \& de Groot, 2005; Peereman \& Content, 1998; Peereman, Lété, \& Sprenger-Charolles, 2007; SprengerCharolles, 2003; Ziegler, Jacobs, \& Stone, 2006; Ziegler et al., 1997). Interestingly, the rate of reading acquisition mirrors the transparency of the writing system with near-to-ceiling performance of Spanish-speaking children after only one year of schooling, intermediate performance for French-speaking children, and relatively poor performance for Englishspeaking children (Goswami, Gombert, \& Barrera, 1998; Seymour, Aro, \& Erskine, 2003). Similar results have been observed with adults for reading speed in a comparison among English-, French- and Italian-speaking normal readers and dyslexics (Paulesu, Démonet, Fazio, McCrory, Chanoine, Brunswick, Cappa, Cossu, Habib, Frith, \& Frith, 2001). Thus, the central question of the present review is to what extent the prevalence and nature of dyslexia subtypes vary across these three languages varying in the consistency of grapheme-phoneme correspondences.

Another issue in the subtyping literature concerns the nature of the control group. Dyslexic performance is usually compared to that of chronological age (CA) controls. In that comparison, the percentage of mixed profiles is expected to be very high, and we should find only very little evidence for dissociated profiles (such as surface or phonological profiles). However, the CA comparison should be supplemented by a comparison with average readers of the same reading level (RL). This is necessary for three reasons. First, reading level has been shown to have an impact on vocabulary size and phonemic awareness (Bryant \& Impey, 1986). Therefore, differences in these skills between dyslexics and CA controls may be merely a consequence of the lower reading level of the dyslexics. Second, there are processing trade-offs in the use of the sublexical and the lexical procedures that depend on the overall level of word recognition attained (e.g., for English-speaking children: Backman, Bruck, Hebert, \& Seidenberg, 1984; Manis, Custodio, \& Szeszulski, 1993; Waters, Seidenberg, \& Bruck, 1984; for French-speaking children: Sprenger-Charolles et al., 2000; SprengerCharolles, Siegel, Béchennec, \& Serniclaes, 2003; Sprenger-Charolles, Siegel, \& Bonnet, 1998). For instance, in two longitudinal studies (Sprenger-Charolles et al., 2000; 2003), children read pseudowords more accurately than high-frequency irregular words when they were 8 years old, whereas the reverse trend was observed two years later. Therefore, the comparisons of dyslexics with either CA or RL controls are based on skills that differ not only quantitatively but also qualitatively. Finally, dyslexics should be compared to RL controls to investigate whether their developmental trajectory is deviant or delayed. The developmental trajectory of the dyslexics is assumed to be delayed rather than deviant when their phonological and orthographic reading skills are at the same level as those of RL controls. It is assumed to be deviant when their phonological or orthographic reading skills are below the level of RL controls. For these three reasons, the present review includes studies with RL controls.

An additional issue concerns the nature of the reading outcome measure. As Share (2008) has noted "it remains to be seen to what extent the classic dual-route distinction between phonological and surface dyslexia... relates to accuracy/speed differences, particularly in the case of more conventional (i.e. consistent) orthographies" (p.592). Some dyslexics may perform like average readers on non-timed measures of pseudoword reading but might show 
robust speed deficits in reading pseudowords. When only accuracy scores are considered, these dyslexics are incorrectly considered as having unimpaired sublexical reading skills. Thus, we have reviewed studies that focused on both latency and accuracy measures.

It should be noted that the present review covers only multiple-case studies, not single-case studies. Multiple-case studies, unlike single-case studies, examine individual cases drawn from a broad population assumed to be representative of the larger population of individuals with dyslexia. Therefore, multiple-case studies are more relevant than single-case studies in assessing the prevalence and the reliability of the different profiles.

Finally, we have only considered studies in which the efficiency of the lexical and the sublexical reading routes have been assessed using the standard way of doing this, that is, with the reading of irregular words versus pseudowords. Studies in which the classification has not been based on pseudoword reading were excluded (e.g. McDougall, Borowsky, MacKinnon, \& Hymel, 2004). However, because in languages with a very transparent orthography it is not possible to find a sufficiently large number of irregular words, we have included in our review a Spanish study in which the efficiency of the lexical reading route has been assessed by highfrequency regular word reading (the prefixe 'ir' in 'irregular' is thus put between '[]' when the Spanish results are presented with the English and French results).

In sum, the reviewed studies are multiple-case studies conducted in languages that vary in orthographic depth. In all but one of the selected studies subtype classifications were based on both CA and RL controls and in the French and Spanish studies both latency and accuracy measures were used as outcome variables.

\section{SYNTHESIS OF THE RESULTS OF THE REVIEWED STUDIES}

The first multiple-case studies were conducted by Seymour (1986, 21 cases of 11- to 25year-old dyslexics) and Snowling, Stackhouse, and Rack (1986b: 7 cases of 8.5- to 40-yearold dyslexics). More recently, there have been seven studies conducted with children that used the same methods (classical and regression-based method: a description of these methods is provided below) to assess the prevalence of the different subtypes in developmental dyslexia (Castles \& Coltheart, 1993; Génard, Mousty, Content, Alegria, Leybaert, \& Morais, 1998; Jiménez, Rodríguez, \& Ramírez, 2009; Manis et al., 1996; Sprenger-Charolles et al., 2000; Stanovich et al., 1997; Ziegler et al., 2008). For the sake of comparability, we have only reviewed these studies. Studies that did not use both the classical and the regression methods (e.g. Bowey \& Rutherford, 2007; Castles, Datta, Gayan, \& Olson, 1999; Sprenger-Charolles, Colé, Kipffer-Piquard, Pinton, \& Billard, 2009), as studies with adult participants (e.g. Milne, Nicholson, \& Corballis, 2003; Zabell \& Everatt, 2002) were not taken into account in the core of our review.

Six of the reviewed studies used irregular word and pseudoword reading skills as indicators of the reliance on each of the two reading routes. Among these studies, five include a CA and RL comparison and four used accuracy only: three with English-speaking children (Castles \& Coltheart, 1993; Manis et al., 1996; Stanovich et al., 1997) ${ }^{2}$; one with French-speaking children (Génard et al., 1998). Another French study used both accuracy and latency (Sprenger-Charolles et al., 2000). In the sixth study, which also involved French-speaking children, there was no RL control group, but both accuracy and speed were examined (Ziegler et al., 2008). We also included the results of a study with Spanish children in which the subtypes have been defined with accuracy scores and processing times for pseudowords versus high frequency regular words, instead of high frequency irregular words (Jiménez et al., 2009). In the Spanish and the two French studies (Sprenger-Charolles et al., 2000; Ziegler et al., 2008), the speed of each correct response was calculated using vocal response latency, that is the delay between the appearance of the word on the screen of the computer and the 
onset of the vocal response ${ }^{3}$.

In the reviewed studies, 337 dyslexics (172 Anglophones, 130 Francophones, and 35 Hispanophones) were compared to 472 CA controls (151 Anglophones, 274 Francophones, and 47 Hispanophones) and 382 RL controls (67 Anglophones and 275 Francophones, and 40 Hispanophones). The large number of children involved in those studies should allow us to reliably estimate the prevalence of the various dyslexic profiles in each of these languages.

The seven studies within the scope of the present review have used two methods to analyze the results, the classical method and the regression method. In the classical method (according to the authors of the studies that were reviewed, children were labeled as phonological dyslexics when only their sublexical reading route (assessed with pseudoword reading) was impaired, and surface dyslexics when only their lexical reading route (assessed with highfrequency irregular-word reading) was impaired; when both routes were deficient, they were said to have a mixed profile. In all the reviewed studies, the cut-off for defining a reading skill as impaired was one standard deviation below the mean of the controls.

In contrast to the classical method, the regression method assesses a relative deficit, either in orthographic skills relative to phonological reading skills, or in phonological reading skills relative to orthographic skills. Stanovich et al. (1997) characterized the subtypes defined in this manner as "soft", as opposed to the "hard" subtypes defined using the classical method. More precisely, soft subtypes are defined by plotting pseudoword performance against irregular-word performance (and vice versa) and then examining the 90\% (or 95\%) confidence intervals around the regression lines determined from the control group. A phonological dyslexic is a child who is an outlier when pseudowords are plotted against irregular words but who is in the normal range when irregular words are plotted against pseudowords. Surface dyslexics are defined in the opposite way. Dyslexics whose scores are outside the confidence intervals in both cases have a mixed profile.

\section{PREVALENCE OF PHONOLOGICAL, SURFACE, AND MIXED PROFILES Chronological Age Comparison}

\section{Hard subtypes (Classical method)}

Table 1 (see also Appendix 2, part 2a) gives the number and the proportion of English-, French-, and Spanish-speaking dyslexics whose reading scores were one standard deviation below (for accuracy, that is less accurate) or above (for speed, that is less rapid) the mean of the CA controls on pseudowords only (hard phonological profile), high-frequency [ir] regular words only (hard surface profile), pseudowords and [ir]regular words (mixed profile), as well as those with no deficit on either assessment.

In terms of accuracy, both pseudoword and [ir]regular-word reading skills were deficient in most English, French, and Spanish dyslexics. Thus, as expected, mixed profiles were the most common across all studies (on average, 65\%: 71\% in English, 63\% in French, 43\% in Spanish) and the overall number of hard dissociated profiles (with either a phonological or a surface profile) was rather small (on average, 26\%: 24\% in English, 28\% in French and 31\% in Spanish). In terms of speed, the results of the French and Spanish samples were very similar, with again more hard mixed profiles (48\% and 54\%, respectively) than hard dissociated profiles (36\% and $25 \%$, respectively).

With regard to the issue of the prevalence of each dissociated profiles, the percentage of hard phonological dyslexics was lower than the percentage of hard surface dyslexics in the accuracy-based French and Spanish studies (6\% versus 22\% in French, 8\% versus 23\% in Spanish), but not in the latency-based French and Spanish studies, in which similar proportions were obtained for phonological and surface dyslexics (16\% versus $20 \%$ in French; 
$11 \%$ versus $14 \%$ in Spanish), as in the accuracy-based English studies (11\% versus 13\%).

Finally, a non negligible number of dyslexics with unimpaired word-level reading skills was observed in transparent writing systems, especially for accuracy (26\% in Spanish, $10 \%$ in French, and 5\% in English; for speed: 20\% in Spanish, 16\% in French, no data available in English).

There were thus cross-language differences and cross-language similarities between the English, French and Spanish studies. These issues are further discussed in the section "Impact of orthographic transparency on subtyping".

Table 1

Chronological Age Comparison (Hard Subtypes): Mean Percentage (and Number) of Different Dyslexic Profiles in English, French, and Spanish for Accuracy and Vocal Response Latency (Cut-off: 1 Standard-Deviation)

\begin{tabular}{|c|c|c|c|c|c|c|c|}
\hline \multicolumn{3}{|c|}{ Accuracy } & & & \multicolumn{3}{|l|}{$\underline{\text { Latency }}$} \\
\hline & English- & French- & Spanish- & Total & French- & $\begin{array}{l}\text { Spanish } \\
-\end{array}$ & Total \\
\hline Total Number & 172 & 130 & 35 & 337 & 55 & 35 & 90 \\
\hline $\begin{array}{l}\text { Phonological } \\
\text { Dyslexics }\end{array}$ & 11 (19) & $06(07)$ & $08(03)$ & $09(29)$ & $16(09)$ & $11(04)$ & 14 (13) \\
\hline $\begin{array}{l}\text { Surface } \\
\text { Dyslexics }\end{array}$ & $13(22)$ & $22(28)$ & $23(08)$ & $17(59)$ & $20(11)$ & $14(05)$ & 18 (16) \\
\hline $\begin{array}{l}\text { Mixed } \\
\text { Profiles }\end{array}$ & $71(122)$ & $63(82)$ & $43(15)$ & 65 (219) & 48 (26) & 54 (19) & $50(45)$ \\
\hline $\begin{array}{l}\text { Without } \\
\text { Deficit }\end{array}$ & 05 (09) & $10(13)$ & $26(09)$ & 09 (31) & $16(09)$ & $20(07)$ & 18 (16) \\
\hline
\end{tabular}

Note. Grey: Higher proportions within a specific category

\section{Soft subtypes (Regression-based method)}

The number and the proportion of the different profiles obtained with the regression method are presented in Table 2 (see also Appendix 2, part 2b). The subtypes reported here were based on accuracy scores in all but two studies because of ceiling effects: (1) the Spanish study by Jiménez et al. (2009), in which $94 \%$ of the dyslexics were classified within the confidence interval, and thus without reading difficulties; (2) one French study (Sprenger-Charolles et al., 2000), in which irregular-word accuracy reached a ceiling level for CA controls. Therefore, the subtypes were based on latencies in these two studies. The latency-based results of the study by Ziegler et al. (2008) are also included in Table 2.

In sharp contrast to the results found with the classical method, those found with the regression method indicated a very low proportion of mixed profiles and a very high proportion of soft dissociated profiles in both the English and French accuracy-based studies: on average $11 \%$ of mixed profiles (16\% in English and 2\% in French); and $61 \%$ of dissociated profiles (64\% in English and 56\% in French). Similar results were obtained in the latency-based French and Spanish studies: on average 1\% of mixed profiles (2\% in French and 0\% in Spanish); and $75 \%$ of dissociated profiles (78\% in French and 69\% in Spanish).

However, unlike the results observed with the classical method, the percentages of each of the two soft dissociated profiles observed with the regression method varied strongly across 
studies, without any clear trend (see Appendix 2, part 2b). For instance, when the classification was based on accuracy scores, soft phonological dyslexics were more prevalent than soft surface dyslexics in one of the English studies (55\% versus 30\% in Castles \& Coltheart, 1993), equally prevalent in the two other English studies (33\% versus 29\% in Manis et al., 1996; 25\% versus 22\% in Stanovich et al., 1997), and much less prevalent in the two French studies in which accuracy scores were examined (4\% versus 56\% in Génard et al., 1998; 17\% versus $29 \%$ in Ziegler et al., 2008).

Finally, there were some dyslexics without any reading deficit in the latency-based French and Spanish studies (20\% in French, 31\% in Spanish). That proportion was higher in the accuracy-based studies: $26 \%$ in English, $41 \%$ in French, and even 94\% in Spanish. The latter result casts doubts on the validity of the use of accuracy-based measures for classifying dyslexics in a very consistent orthography, at least when the regression method is used.

\section{Table 2}

Chronological Age Comparison (Soft Subtypes): Mean Percentage (and Number) of Different Dyslexic Profiles in English, French, and Spanish for Accuracy and Vocal Response Latency

\begin{tabular}{llllllll} 
& Accuracy & \multicolumn{8}{c}{ Latency } \\
\hline & English- & French- & Spanish- *Total & French- & Spanish- & Total \\
\hline $\begin{array}{l}\text { Total Number } \\
172\end{array}$ & 99 & 35 & 271 & 55 & 35 & 90 \\
\hline $\begin{array}{l}\text { Phonological } \\
\text { Dyslexics }\end{array}$ & $37(63)$ & $07(07)$ & $03(01)$ & $26(70)$ & $40(22)$ & $23(08)$ & $34(30)$ \\
$\begin{array}{l}\text { Surface } \\
\text { Dyslexics }\end{array}$ & $27(46)$ & $49(49)$ & $03(01)$ & $35(95)$ & $38(21)$ & $46(16)$ & $41(37)$ \\
$\begin{array}{l}\text { Mixed } \\
\text { Profiles }\end{array}$ & $16(27)$ & $02(02)$ & $00(00)$ & $11(30)$ & $02(01)$ & $00(00)$ & $01(01)$ \\
$\begin{array}{l}\text { Without } \\
\text { Deficit }\end{array}$ & $21(36)$ & $41(41)$ & $94(33)$ & $28(77)$ & $20(11)$ & $31(11)$ & $24(22)$ \\
\hline
\end{tabular}

Note. Grey: Higher proportions within a specific category

* Without the results of the Spanish-speaking children

\section{Reading Level Comparison: Soft subtypes (Regression-based method)}

The outcomes of comparisons with RL controls are presented in Table 3 (see also Appendix 2, part 2c). In the quoted studies, only the data from the regression method were examined. This choice, made in all the reviewed studies including a RL comparison, is motivated by the fact that one of the aims of these studies was to examine dissociated profiles. Since, on the one hand, the number of dyslexics with a dissociated profile found with the classical method in the CA comparison was low and, on the other hand, the number of dyslexics with impaired reading skills decreased from the CA to the RL comparison, the sole possible mean to find a high number of dissociated profiles in the RL comparison was to use the regression method.

The most significant finding was that, based on accuracy, the percentage (and the number) of soft phonological dyslexics remained non negligible, whatever the language (8\% to 29\%), whereas the soft surface profiles almost disappeared, again whatever the language $(0 \%$ to 3\%): 53 phonological profiles and 4 surface dyslexics among 234 dyslexics. A similar result was found with speed as the measure, where the proportion of phonological versus surface dyslexics was $39 \%$ versus $10 \%$ in French (12 cases versus 3 cases) and 34\% versus 14\% in 
Spanish (12 cases versus 5 cases). Another important finding was that the proportion of dyslexics with no deficit in either pseudowords or [ir] regular words was very high in all studies, either for accuracy (on average, 76\%: 68\% in English, and 92\% in French) or for speed (52\% both in French and in Spanish). Thus, most of the dyslexics have a delayed profile. These results will be discussed in the last section of the review. Next, we will address another important issue in the neuropsychological literature: the reliability of the two dissociated profiles.

Table 3

Reading Level Comparison (Soft Subtypes): Mean Percentage (and Number) of Different Dyslexic Profiles in English, French, and Spanish for Accuracy and Vocal Response Latency

\begin{tabular}{|c|c|c|c|c|c|c|c|}
\hline & Accuracy & & & & Latency & & \\
\hline & English- & French- & *Spanish- & Total & French- & Spanish- & Total \\
\hline Total Number & 159 & 75 & & 234 & 31 & 35 & 66 \\
\hline $\begin{array}{l}\text { Phonological } \\
\text { Dyslexics }\end{array}$ & $29 \quad(47)$ & $08(06)$ & -- & $23 \quad(53)$ & 39 (12) & 34 (12) & $36(24)$ \\
\hline $\begin{array}{l}\text { Surface } \\
\text { Dyslexics }\end{array}$ & $03 \quad(04)$ & $00(00)$ & -- & $02 \quad(04)$ & $10(03)$ & $14(05)$ & $12(08)$ \\
\hline $\begin{array}{l}\text { Mixed } \\
\text { Profiles }\end{array}$ & $00 \quad(00)$ & $00(00)$ & -- & $00 \quad(00)$ & $00(00)$ & $00(00)$ & $00(00)$ \\
\hline $\begin{array}{l}\text { Without } \\
\text { Deficit }\end{array}$ & $68(108)$ & 92 (69) & -- & $76(177)$ & 52 (16) & $52(18)$ & $52(34)$ \\
\hline
\end{tabular}

Note. Grey: Higher proportions within a specific category

* Not examined because of the very high level of accuracy

\section{ASSESSMENTS OF THE RELIABILITY OF PHONOLOGICAL AND SURFACE PROFILES}

One approach to test the reliability of a classification is to use 'validation measures' that are related to the hypothesized reading deficits but independent of the tasks used to classify the subjects. Such additional evaluations of dyslexics' reading and reading-related skills were conducted in English (Manis et al., 1996; Stanovich et al., 1997), French (Sprenger-Charolles et al., 2000; Ziegler et al., 2008), and Spanish (Jiménez et al., 2009). These analyses were based on the data from the dyslexic children who exhibited a soft dissociated profiles according to the regression method in the CA comparison (see Table 2 and Appendix 2, Part b): 17 phonological dyslexics and 15 surface dyslexics in the accuracy-based study by Manis et al. (1996) and by Stanovich et al. (1997); 4 phonological dyslexics and 7 surface dyslexics in the accuracy-based study by Ziegler et al. (2008); 16 phonological dyslexics and 10 surface dyslexics in the latency-based study by Sprenger-Charolles et al. (2000); 8 phonological dyslexics and 16 surface dyslexics in the latency-based study by Jiménez et al. (2009).

\section{Reading skills}

The most significant findings came from the RL comparisons (not considered in the study by Ziegler et al., 2008), in which the phonological reading skills of soft phonological dyslexics were always found to be inferior, but the orthographic skills of soft surface dyslexics 
were not, except in one study (Jiménez et al., 2009): in that study, surface dyslexics were found to perform significantly more poorly than RL controls in a homophone choice task that was designed to assess the efficiency of the lexical route. In all the other studies, the orthographic skills of soft surface dyslexics were never below those of the RL controls, whereas the phonological reading skills of soft phonological dyslexics were always below them. For example, in the study with English-speaking children by Stanovich et al. (1997, see Stanovich et al., 1997, Tables 4 and 5, p.122), the phonological reading skills of the soft phonological dyslexics were lower than those of the RL controls, not only on the phonological reading task used to define the profile, but also on another assessment of their phonological reading skills (the Word Attack subtest of the Woodcock, 1987). In contrast, the orthographic reading skills of the soft surface dyslexics were not lower than those of the RL controls, once again not only on the orthographic task used to define the profile, but also on other assessments of their orthographic reading skills (the Word Identification subtest of the Woodcock, 1987, plus an experimental wordlikeness choice task). Similar results were observed in English study by Manis et al. (1996).

In the French study by Sprenger-Charolles et al. (2000), the two groups of dyslexics with soft dissociated profiles based on the comparison with CA controls were compared to RL controls on the measure used to define their profiles (irregular word versus pseudoword latencies) and on another measure (irregular word versus pseudoword accuracy scores). The results indicated that the irregular-word scores of the soft surface dyslexics, but also those of the soft phonological dyslexics, did not fall significantly below those of the RL controls, whether on accuracy or on speed. In sharp contrast, both groups of dyslexics obtained lower scores in pseudoword reading than the RL controls, in terms of speed for the soft phonological dyslexics (the measure used to define their profiles), in terms of accuracy for the soft surface dyslexics (a measure not used to define their profiles).

\section{Reading-Related skills}

The difficulties experienced by dyslexics in reading new words are generally explained in terms of their poor phonological skills outside the reading domain, especially in phonemic awareness. This deficit may hinder the acquisition of the sublexical reading procedure which requires the ability to connect sublexical written units (graphemes) to their corresponding sublexical spoken units (phonemes).

Phonemic awareness was assessed in five studies (Jiménez et al., 2009; Manis et al., 1996; Sprenger-Charolles et al., 2000; Stanovich et al., 1997; Ziegler et al., 2008). A phonemic awareness deficit that was specific to phonological dyslexics was observed only in the two studies (Stanovich et al., 1997; Manis et al., 1996). For instance, in the study by Stanovich et al. (1997), which involved a syllable and phoneme deletion task, the phonological awareness scores of the phonological, but not the surface dyslexics', lagged behind those of the RL controls. As well, in the study by Manis et al. (1996) only phonological dyslexics performed more poorly than RL controls in a phonemic awareness task. In contrast, in the Spanish study by Jiménez et al. (2009) both phonological and surface dyslexics scored significantly lower than CA and RL controls in phonemic awareness tasks. Similarly, in the French study by Ziegler et al. (2008), surface dyslexics exhibited deficits in phonemic awareness tasks, and this deficit was not significantly different from that of phonological dyslexics. Finally, in the French longitudinal study by Sprenger-Charolles et al. (2000), future dyslexics (with either a phonological or a surface profile) and future average readers were given a phonemic deletion task at age 5. The scores of the future phonological dyslexics were not lower than those of the future surface dyslexics, both groups performing less well than the future average readers. The findings that sometimes surface dyslexics were found to have deficient phonemic skills is 
examined more thoroughly below.

\section{POSSIBLE EXPLANATIONS}

The present review highlights six major findings concerning the prevalence and the reliability of the subtypes. The first two, linked to the CA comparisons, are contradictory: the classical method consistently revealed a high percentage of mixed profiles and a low percentage of dissociated profiles, irrespective of the measure (accuracy or speed) and the language; exactly the opposite pattern was observed with the regression method. Two other findings are related to the soft dissociated profiles found in the RL comparisons: regardless of language and measure, the percentage of soft phonological profiles remained quite high, and the phonological reading skills of the soft phonological dyslexics were always lower than those of the RL controls; in contrast, again regardless of language and measure, the soft surface profiles almost disappeared and the orthographic skills of the soft surface dyslexics were not lower than those of the RL controls, except in one study (Jiménez et al., 2009). The fifth finding is linked to the fact that a deficiency in phonemic awareness has been reported not only in the soft phonological profiles, but also in the soft surface profiles, at least in some studies (e.g., Jiménez et al., 2009; Sprenger-Charolles et al., 2000; Ziegler et al., 2008). Finally, cross-language differences were evident in the distribution of the dissociated profiles. For instance, when the classification was based on accuracy scores, the percentages of hard and soft phonological dyslexics was below those of hard and soft surface dyslexics in the French and Spanish studies (Génard et al., 1998; Jiménez et al., 2009; Sprenger-Charolles et al., 2000; Ziegler et al., 2008), but not in the English studies (Castles \& Coltheart, 1993: Manis et al., 1996; Stanovich et al., 1997).

\section{Impact of the Method of Classification on Subtyping}

One surprising finding concerns the fact that the regression method revealed a high proportion of dyslexics with no reading difficulties. For instance, when the classification was based on accuracy scores, this percentage was as high as $94 \%$ in the Spanish study (Jiménez et al., 2009), as compared to $26 \%$ for the classical method in the same study and with the same children and the same measure. Therefore, as noted by Jiménez et al. (2009, p.10) "accuracy scores are not appropriate for classifying dyslexic subtypes in a consistent orthography", at least when the regression approach is used. This is because that method relies on correlations, which are very sensitive to ceiling (and floor) effects ${ }^{4}$. This result could also be due to the fact that, with the regression method, an individual whose scores for errors fell within the confidence interval of the regression line, but on the very high part of that line, could be considered as having unimpaired skills in the domains used for subtyping, as illustrated by the cases Charlie and Fred (see Bates, Appelbaum, Salcedo, Saygin, and Pizzamiglio, 2003): Charlie's scores in skills X and Y used for the subtyping are more than 2 SDs above those of the controls in the measure Y, and just 2 SDs above in the measure X; in contrast, Fred's scores are $1 \mathrm{SD}$ above the mean of the same control group in the measure $\mathrm{X}$, and within the normal range in the measure Y. In spite of the fact that Charlie's impairments are more severe than Fred's impairments, it is Fred who lies outsides the cloud of points that indicates the degree of the correlation between scores on performance $\mathrm{X}$ and $\mathrm{Y}$ in the control group, whereas Charlie falls within the same cloud of points (see Bates et al., 2003, Figure 3, p.1133).

Another concern is that the regression method revealed a majority of dissociated profiles, while the classical method revealed a majority of mixed profiles, as expected. One obvious reason for this discrepancy is that the regression method is designed to search for dissociated profiles, as noted by the researchers that have pioneered that method (Castles \& Coltheart, 
1993, see the beginning of the second paragraph, p.168), and explicitely stated by those who have used and discussed it (e.g. Stanovich et al., 1997). For instance, Stanovich et al. (1997, p.115) explained that "additional cases of subtypes could be identified, not on the basis of abnormal performance on one measure and normal performance on the other, but on relative imbalances on the two tasks among children who might well show depressed performance on both". This result is actually observed in all studies that were reviewed (see Table 2 compared to Table 1).

Finally minor differences between studies may be attributable to differences between samples, with more or less individuals with extreme discrepancies between lexical and sublexical reading skills, as suggested by correlation analyses. For instance, correlations between irregular word and pseudoword in the dyslexic samples of Castles and Coltheart (1993), and Manis et al. (1996), were respectively .11 and .36, thus suggesting that there were more individual with extreme discrepancies between lexical and sublexical reading skills in the first study as compared to the second (see Manis et al., 1996, p.22).

\section{Impact of Orthographic Transparency on Subtyping}

The results obtained for accuracy indicated that, as the degree of the transparency of the orthography increased so did the proportion of dyslexics without any apparent deficit at the word level. Indeed, the Spanish study showed the highest proportion of dyslexics with unimpaired reading skills. In addition to the explanation already provided, the Spanish results could be due to the fact that the Spanish classification was based on high frequency regular words and pseudowords. High frequency regular words could be read by both the lexical and the sublexical reading route, and thus lead to a fewer number of errors than high frequency irregular words. This result has been observed in studies with unimpaired readers (e.g. for French-speaking children, Sprenger-Charolles et al., 2003), as well as in studies with dyslexic children (e.g. for French-speaking dyslexic children, Sprenger-Charolles et al., 2009). Furthermore, the Spanish orthography is highly regular. Therefore, the Spanish children could also obtain a very high level of performance for pseudoword reading, at least for accuracy. The fact that the French results were in between the Spanish and the English results is an indicator of the impact of the degree of opacity of the orthography on the apparent severity of the dyslexics' reading difficulties.

Another major finding concerns the systematic differences in the proportion of soft dissociated profiles across transparent and opaque writing systems. In the accuracy-based studies conducted in transparent orthographies (Spanish and even French), surface dyslexics were more frequent than phonological dyslexics. Alternatively, no such systematic differences between the proportion of phonological and surface dyslexics were obtained in the accuracybased English studies, as in the latency based French and Spanish studies. We believe that these findings reflect a measurement artefact due to the fact that pseudoword reading in transparent orthographies (Spanish and French) is much easier than in opaque orthographies (English); indeed, pseudoword accuracy for dyslexics in transparent languages is often at ceiling (e.g. Jiménez et al., 2009; Sprenger-Charolles et al., 2000; Ziegler et al., 2003a). This does not mean that phonological decoding deficits do not exist in transparent orthographies but rather that reading speed has to be considered to detect such a deficit (e.g. Jiménez \& Hernández-Valle, 2000; Jiménez et al., 2009; Jiménez \& Ramirez, 2002; Sprenger-Charolles et al., 2000; Serrano, \& Defior, 2008).

\section{Reliability of Phonological and Surface profiles}

In the RL comparison, the proportion of phonological dyslexics remained quite high, whereas the surface profile almost disappeared. This finding suggests that the developmental 
trajectory of most phonological dyslexics is deviant, whereas the one of most surface dyslexics is delayed. This conclusion is also supported by the analyses of the deficits associated with these two profiles. For instance, the orthographic skills of the surface dyslexics were not different from those of RL controls, except in the study by Jiménez et al. (2009), a result that could be due to poor home literacy experience (the parents of children with a surface profile reported less home literacy experiences than the parents of the RL controls).

In contrast, the phonological reading skills of soft phonological dyslexics systematically fell below those of RL controls (e.g. Manis et al., 1996; Stanovich et al., 1997; SprengerCharolles et al., 2000). In some studies, even the phonological reading skills of soft surface dyslexics were inferior to those of RL controls (e.g. Sprenger-Charolles, 2000). In addition, in the studies in which phonemic awareness was assessed (Jiménez et al., 2009; Manis et al., 1996; Sprenger-Charolles et al., 2000; Stanovich et al., 1997; Ziegler et al., 2008) a phonological deficit was found in phonological dyslexics, and even in surface dyslexics, at least in three of these studies (Jiménez et al., 2009; Sprenger-Charolles et al., 2000; Ziegler et al., 2008). Since phonological deficits were observed in surface profiles, these profiles appear to be less reliable than the phonological profiles.

The claim that the developmental trajectory of the phonological dyslexics is deviant, whereas that of the surface dyslexics is delayed is supported by results of studies not included in our review: for instance, results from multi-case studies (e.g. Bowey \& Rutherford, 2007; Manis, \& Bailey, 2008) and from single-case studies (e.g., Snowling, Goulandris, Bowlby, \& Howel, 1986a; Temple \& Marshall, 1983, according to Bryant \& Impey's re-analyses, 1986; Valdois, Bosse, Ans, Carbonnel, Zorman, David, \& Pellat, 2003). These studies also suggest that the surface profile is less reliable than the phonological profile. Indeed, phonological deficits have been reported in some single cases of surface dyslexia (e.g., Coltheart, Masterson, Byng, Prior, \& Riddoch, 1983, according to Bryant \& Impey's re-analyses, 1986) and in some multi-case studies (e.g. Zabell \& Everatt, 2002; Bailey, Manis, Pedersen, \& Seidenberg, 2003). For instance, in the study with adult participants by Zabell and Everatt (2002), surface dyslexics were found to behave in the same way as phonological dyslexics on four tasks requiring phonological processing, especially in pseudoword reading and phonological awareness. In the study by Bailey et al. (2003) surface dyslexics exhibited a tendency to score lower than RL controls on pseudoword reading. Longitudinal data also indicated that surface profiles were less stable than phonological profiles (e.g., Manis \& Bailey, 2008; Sprenger-Charolles et al., 2000), which led Manis and Bailey (2008) to suggest that there is "a core subgroup with selective phonological deficits that is relatively stable and easy to identify" (p.171), which is not the case for the surface profile.

One possible explanation of these results is that the surface profile may be due to both a slight phonological impairment and aggravating environmental factors. As suggested by Stanovich et al. (1997; see also Stanovich, 1999), children from a disadvantaged social background may not only be less frequently exposed to written material but may also be given less help in overcoming their reading deficiency than children from a social environment likely to motivate them to learn to read despite their difficulties. Thus, as also noted by Harm and Seidenberg (1999), the combination of mild phonological deficits and lack of reading opportunity could lead to the surface profile. This account could explain why surface dyslexics are often found to have impaired phonological reading skills, in addition to impaired orthographic reading skills, the last impairment being explained by the fact that the acquisition of well-defined orthographic representations needs frequent exposure to print.

As we have already noted, this explanation is supported by the fact that, in the study by Jiménez et al. (2009), the orthographic deficit observed in surface dyslexics as compared to 
RL control was found to be associated with poor home literacy experience. Additional support for this interpretation is reported in the large scale twin study by Castles et al. (1999), in which two subgroups of dyslexics with a dissociated profile (approximately 300 surface and 300 phonological dyslexics) were selected among a group of almost 1000 dyslexics. In the two measures used to assess lexical reading skills as well as in a measure of print exposure, the scores of the surface dyslexics were systematically lower than those of the phonological dyslexics. The influence of environmental versus genetic factors was assessed by the exam of the relations between the reading deficits of the monozygotic versus the dyzygotic twins. The results indicated a small but significant part of the genetic component together with a large influence of the environment in surface dyslexics, and the reverse pattern for the phonological dyslexics. These results thus support accounts of surface dyslexia that emphasize a strong environmental contribution.

\section{Conclusion}

The findings of the reviewed studies are not consistent with the idea that clear-cut subtypes can be detected in developmental dyslexia. However, further progress should be made in order to help not only researchers but also clinicians to correctly diagnose dissociated profiles.

Firstly, it is necessary to measure the reliability of each of the dissociated profiles. This should be accomplished by the use of validation measures which are related to the hypothesized deficits but independent of the tasks used to classify the subjects (e.g. Bates et al., 2003). This precaution has been taken into account in most of the studies presented in our review (e.g., Jiménez et al., 2009; Manis et al., 2006; Sprenger-Charolles et al., 2000; Stanovich et al., 2007; Ziegler et al., 2008).

Secondly, it is necessary to more precisely assess the strength of the dissocation in each dissociated profile, that is the magnitude of the difference between the scores obtained by each dyslexic on tasks used to measure the dissociation between his/her lexical and phonological reading skills. This methodological issue has been previously addressed in the context of acquired disorders (Bates et al., 2003; Crawford \& Garthwaite, 2005; Crawford, Garthwaite, \& Gray, 2003; Crawford, Garthwaite, \& Howell, 2009) $)^{5}$. It is obvious that case studies of developmental disorders need to consider that issue.

Finally, the fact that assessments solely based on accuracy could lead to misclassification indicates that it is necessary to also consider speed to diagnose dyslexia. This is an important issue since slow processing speed reflects poorly automated reading skills, which is perhaps the unique long-term signature of developmental dyslexia (Shaywitz, \& Shaywitz, 2005). Our results also show that dissociated profiles can be obtained when speed is used as the dependent variable, which argues against the claim that the classic dual-route distinction between phonological and surface dyslexia is "a purely accuracy-based dichotomy" (Share, 2008, p.592). 


\section{NOTES}

1. The dual-route model has also been applied to languages other than English (e.g., Ziegler, Perry \& Coltheart, 2000; 2003b)

2. Processing speed can only be used when the number of correct responses is not too low (less than 50\%, see Olson, Forsberg, Wise, \& Rack, 1994). This could explain why in most studies with dyslexic children, especially ones in English, only accuracy is taken into account.

3 . In a recent review, Share $(2008$, p.593) has noted that to assess reading speed, the use of vocal response latency is a "standard practice ... in the English language literature... whereas in regular orthographies, a case could be made for using voice offset" (as in the study by Landerl, Wimmer, \& Frith, 1997). Furthermore, Share (2008) added that vocal response latencies might be biased by "false starts, self corrections and hesitations" (p.593). However, vocal response latency (and not voice offset) has been used in language with a transparent orthography (French: e.g., Sprenger-Charolles et al., 2000 and 2003; Sprenger-Charolles, Colé, Béchennec, \& Kipffer-Piquard, 2005; Ziegler et al., 2008); German: e.g. Ziegler et al., 2003a; Spanish: e.g., Jiménez et al., 2009). In addition, in all of the above cited studies, latencies were computed off-line using the speech signal, which makes it possible to listen to the recording and thus to detect false starts, self corrections and hesitations. Therefore, vocal response latency might not be biased by "false starts, self corrections and hesitations" (the latency of the vocal response being not taken into account in these cases).

4. See the method proposed by Crawford and Garthwaite (2005) to deal with negative skew, that are common in control data because the tasks used often measure abilities that are largely within the competence of unimpaired participants, and thus yield ceiling effects.

5. For instance, with the classical method, a dyslexic whose irregular and pseudoword reading scores are respectively $-0.80 \mathrm{SD}$ versus $-1.30 \mathrm{SD}$ below the means of the control will be considered has having a phonological profile just like a dyslexic with scores at $-0.50 \mathrm{SD}$ and $-4.50 \mathrm{SDs}$ below the same means. Both are classified as phonological dyslexics although the difference between pseudoword and irregular word reading is ten times greater in the second case than in the first (for suggestions to deal with that issue, see, Crawford et al., 2003; Crawford, \& Garthwaite, 2005). Another important question is that of the correlations within the normative sample. As explained by Bates et al. (2003) "the number of dissociations we are able to detect is systematically related to the magnitude of the correlations between measures. If the correlation is low (approaching zero) we are able to find a relatively large number of dissociations. However, this is not necessary a good thing: low correlations may reflect a true and meaningful form of independence between measures, but they may also reflect high measurement unreliability. ... By contrast, if the correlation between the measures is high, then dissociations are much more difficult to detect" (p.1150), and some adjustments are necessary (see Bates et al, 2003; Crawford et al., 2003; Crawford, \& Garthwaite, 2005). 


\section{REFERENCES}

Backman, J., Bruck, M., Hebert, M., \& Seidenberg, M. S. (1984). Acquisition and use of spelling sound correspondences in reading. Journal of Experimental Child Psychology, 38, 114-133.

Bailey, C. E., Manis, F. R., Pedersen, W. C., \& Seidenberg, M. S. (2003). Variations among developmental dyslexics: Evidence from a printed-word-learning task. Journal of Experimental Child Psychology, 87, 125-154.

Bates, E., Appelbaum, M., Salcedo, J., Saygin, A.P., \& Pizzamiglio, L. (2003). Quantifying Dissociations in Neuropsychological Research. Journal of Clinical and Experimental Neuropsychology, 25, 1128-1153.

Bergmann J., \& Wimmer, H. (2008). A dual-route perspective on poor reading in a regular orthography: evidence from phonological and orthographic lexical decisions. Cognitive Neuropsychology, 25(5), 653-676.

Borgwaldt, S. R., Hellwig, F. M., \& De Groot, A. M. B. (2005). Onset entropy matters letter-to-phoneme mappings in seven languages. Reading and Writing, 18, 211-229.

Bowey, J. A., \& Rutherford, J. (2007). Imbalanced word-reading profiles in eighth-graders. Journal of Experimental Child Psychology, 96(3), 169-196.

Bryant, P., \& Impey, L. (1986). The similarities between normal readers and developmental and acquired dyslexics. Cognition, 24, 121-137.

Castles, A., \& Coltheart, M. (1993). Varieties of developmental dyslexia. Cognition, 47, 149180.

Castles, A., Datta, H., Gayan, J., \& Olson, R. K. (1999). Varieties of reading disorder: Genetic and environmental influences. Journal of Experimental Child Psychology, 72, 73-94.

Coltheart, M., Curtis, B., Atkins, P., \& Haller, M. (1993). Models of reading aloud: Dual route and parallel processing approaches. Psychological Review, 100, 589-608.

Coltheart, M., Masterson, J., Byng, S., Prior, M., \& Riddoch, J. (1983). Surface dyslexia. Quarterly Journal of Experimental Psychology, 35, 469-595.

Coltheart, M., Rastle, K., Perry, C., Langdon, R., \& Ziegler, J. (2001). DRC: A dual route cascaded model of visual word recognition and reading aloud. Psychological Review, 108, 204-256.

Crawford, J. R., \& Garthwaite, P. H. (2005). Evaluation of criteria for classical dissociations in single-case studies by Monte Carlo simulation. Neuropsychology, 19, 664-678.

Crawford, J. R., Garthwaite, P. H., \& Gray, C. D. (2003). Wanted: Fully operational definitions of dissociations in single-case studies. Cortex, 39, 357-370.

Crawford, J. R., Garthwaite, P. H., \& Howel, D.C. (2009). On comparing a single case study with a control sample: An alternative perspective. Neuropsychology, 47, 2690-2695.

Génard, N., Mousty, P., Content, A., Alegria, J., Leybaert, J., \& Morais, J. (1998). Methods to establish subtypes of developmental dyslexia. In P. Reitsma, \& L. Verhoeven (Eds.), Problems and interventions in literacy development (pp. 163-176). Dordrecht: Kluwer.

Goswami, U., Gombert, J. E., \& Barrera, L. F. (1998). Children's orthographic representations and linguistic transparency: Nonsense word reading in English, French and Spanish. Applied Psycholinguistics, 19, 19-52.

Harm, M. W., \& Seidenberg, M. S. (1999). Phonology, reading acquisition, and dyslexia: Insights from connectionist models. Psychological Review, 106, 491-528.

Jiménez, J. E., \& Hernández-Valle, I. (2000). Word identification and reading disorders in the Spanish language. Journal of Learning Disabilities, 32, 267-275.

Jiménez, J. E., \& Ramírez, G. (2002). Identifying subtypes of reading disability in the Spanish language. The Spanish Journal of Psychology, 5, 3-19.

Jiménez, J. E., Rodríguez, C., \& Ramírez, G. (2009). Spanish developmental dyslexia: 
Prevalence, cognitive profile and home literacy experiences. Journal of Experimental Child Psychology. 103(2), 167-185.

Landerl, K., Wimmer, H., \& Frith, U. (1997). The impact of orthography consistency on dyslexia: A German-English comparison. Cognition, 63, 315-334.

Manis, F. R., \& Bailey, C. E. (2008). Exploring heterogeneity in developmental dyslexia: A longitudinal investigation. In G. Reid, A.J. Fawcett, L. S. Siegel, \& F. Manis (Eds.), The Sage Handbook of Dyslexia (pp. 149-173). London: Sage Publications Ltd.

Manis, F. R., Custodio, R., \& Szeszulski, P. A. (1993). Development of phonologic and orthographic skills: A 2-year longitudinal study of dyslexic children. Journal of Experimental Child Psychology, 56, 64-86.

Manis, F. R., Seidenberg, M. S., Doi, L. M., McBride-Chang, C., \& Peterson, A. (1996). On the basis of two subtypes of developmental dyslexia. Cognition, 58, 157-195.

McDougall, P., Borowsky, R., MacKinnon, G. E., \& Hymel, S. (2004). Process dissociation of sight vocabulary and phonetic decoding in reading: A new perspective on surface and phonological dyslexias. Brain and Language, 92, 185-203.

Milne, R. D., Nicholson, T., \& Corballis, M. C. (2003). Lexical access and phonological decoding in adult dyslexic subtypes. Neuropsychology, 17, 362-368.

Olson, R. K., Forsberg, H., Wise, B., \& Rack, J. (1994). Mesurement of word recognition, orthographic and phonological skills. In G. R. Lyon (Ed.), Frames of reference for the assessment of learning desabilities: New views on measurement issues (pp. 243-275). Baltimore/London: Paul H. Brookes.

Paulesu, E., Démonet, J.-F., Fazio, F., McCrory, E., Chanoine, V., Brunswick, N, Cappa, S. F., Cossu, G., Habib, M., Frith, C. D., \& Frith, U. (2001). Dyslexia, Cultural diversity and Biological unity. Science, 291, 2165-2167.

Peereman, R., \& Content, A. (1998). Quantitative analysis of orthography to phonology mapping in English and French (on-line). http://homepages.vub.ac.be/ acontent/OPMapping.html.

Peereman, R., Lété, B., \& Sprenger-Charolles, L. (2007). Manulex-infra: Distributional characteristics of infra-lexical and lexical units in child-directed written material. Behavior Research Methods, Instruments and Computers, 39, 593-603.

Plaut, D. C., McClelland, J. L., Seidenberg, M. S., \& Patterson, K. E. (1996). Understanding normal and impaired word reading: Computational principles in quasi-regular domain. Psychological Review, 103, 56-115.

Rack, J. P., Snowling, M. J., \& Olson, R. K. (1992). The nonword reading deficit in developmental dyslexia: A review. Reading Research Quarterly, 27, 29-53.

Seidenberg, M. S., \& McClelland, J. L. (1989). A distributed developmental model of word recognition and naming. Psychological Review, 96, 523-568.

Serrano, F.D., \& Defior, S. (2008). Dyslexia speed problems in a transparent orthography. Annals of Dyslexia, 58, 81-95.

Seymour, P. H. K. (1986). A cognitive analysis of dyslexia. London: Routledge and Kegan Paul.

Seymour, P. H. K., Aro, M., \& Erskine, J. M. (2003). Foundation literacy acquisition in European orthographies. British Journal of Psychology, 94, 143-174.

Share, D. L. (1995). Phonological recoding and self-teaching: Sine qua non of reading acquisition. Cognition, 55, 151-218.

Share, D. L. (2008). On the Anglocentrism of current reading research and practice: The perils of overreliance on an "outlier orthography". Psychological Bulletin, 134, 584-615.

Shaywitz, S.E., \& Shaywitz, B.A. (2005). Dyslexia (Specific Reading Disability). Biological Psychiatry, 57, 1301-1309. 
Siegel, L. S. (1993). Phonological processing deficits in reading as the basis of a reading disability. Developmental Review, 13, 246-257.

Siegel, L. S. (1998). Phonological processing deficits and reading disabilities. In J. L. Metsala, \& L. C. Ehri (Eds.), Word Recognition in Beginning Literacy (pp.141-160). Mahwah, NJ, Lawrence Erlbaum Associates.

Siegel, L. S. (1999). Issues in the definition and diagnosis of learning disabilities. Journal of Learning Disabilities, 22, 469-478.

Snowling, M. J., Goulandris, N., Bowlby, M., \& Howel, P. (1986a). Segmentation and speech processing in relation to reading skills: A developmental analysis. Journal of Experimental Child Psychology, 41, 489-507.

Snowling, M. J., Stackhouse, J., \& Rack, J. (1986b). Phonological dyslexia and dysgraphia: A developmental analysis. Cognitive Neuropsychology, 3, 309-339.

Sprenger-Charolles, L. (2003). Reading acquisition: Cross linguistic data. In T.Nunes, \& P.Bryant (Eds.), Handbook of children's literacy (pp. 43-66). Dordrecht: Kluwer.

Sprenger-Charolles, L., Colé, P., Béchennec, D., \& Kipffer-Piquard, A. (2005). French normative data on reading and related skills from EVALEC, a new computerized battery of tests (end Grade 1, Grade 2, Grade 3, and Grade 4). European Review of Applied Psychology, 55(3), 157-186.

Sprenger-Charolles, L., Colé, P., Kipffer-Piquard, A., Pinton, F., \& Billard, C. (2009). Reliability and prevalence of an atypical development of phonological skills in Frenchspeaking dyslexics. Reading and writing: An interdisciplinary journal, 22(7), 811-842.

Sprenger-Charolles, L., Colé, P., Lacert, P., \& Serniclaes, W. (2000). On subtypes of developmental dyslexia: Evidence from processing time and accuracy scores. Canadian Journal of Experimental Psychology, 54, 88-104.

Sprenger-Charolles, L., Colé, P., \& Serniclaes, W. (2006). Reading acquisition and developemental dyslexia (Essays in developmental psychology). Psychology Press, Hove, UK, and New-York, USA (Taylor \& Francis)

Sprenger-Charolles, L., Siegel, L. S., Béchennec, D, \& Serniclaes, W. (2003). Development of phonological and orthographic processing in reading aloud, in silent reading and in spelling: A four year longitudinal study. Journal of Experimental Child Psychology, 84, 194-217.

Sprenger-Charolles, L., Siegel, L. S., \& Bonnet, P. (1998). Reading and spelling acquisition in French: The role of phonological mediation and orthographic factors. Journal of Experimental Child Psychology, 68, 134-165.

Stanovich, K. E (1999). The sociopsychometrics of learning disabilities. Journal of Learning Disabilities, 32, 350-361.

Stanovich, K. E., \& Siegel L. S. (1994). Phenotypic performance profile of children with reading disabilities: A regression-based test of the phonological-core variable-difference model. Journal of Educational Psychology, 86, 24-53.

Stanovich, K. E., Siegel, L. S., \& Gottardo, A. (1997). Converging evidence for phonological and surface subtypes of reading disability. Journal of Educational Psychology, 89, 114127.

Temple, C. M., \& Marshall, J. C. (1983). A case study of developmental phonological dyslexia. British Journal of Psychology, 74, 517-533.

Valdois, S., Bosse, M. L., Ans, B., Carbonnel, S., Zorman, M., David, D., \& Pellat, J. (2003). Phonological and visual processing deficits can dissociate in developmental dyslexia: Evidence from two case studies. Reading and Writing: An Interdisciplinary Journal, 16, 541-572.

Waters, G. S., Seidenberg, M. S., \& Bruck, M. (1984). Children's and adults' use of spelling 
sound information in three reading tasks. Memory \& Cognition, 12, 293-305.

Woodcock, R.W. (1987). Woodcock Rending Mastery Tests-- Revised. Circle Pines, MN: American Guidance Service.

Zabell, C., \& Everatt, J. (2002). Surface and phonological subtypes of adult developmental dyslexia. Dyslexia, 8, 160-177.

Ziegler, J. C., Bertrand, D., Tóth, D., Csépe, V., Reis, A., Faísca, L., et al. (2010). Orthographic depth and its impact on universal predictors of reading: A cross-language investigation. Psychological Science, 21, 551-559.

Ziegler, J. C., Castel, C., Pech-Georgel, C., George, F., Alario, F.X., \& Perry, C. (2008). Developmental dyslexia and the Dual Route Model of reading: Simulating Individual differences and subtypes. Cognition, 107, 151-178.

Ziegler, J., \& Goswami, U. (2005). Reading acquisition, developmental dyslexia and skilled reading across languages: A psycholinguistic grain size theory. Psychological Bulletin, 131, 3-29.

Ziegler, J. C., Jacobs, A. M., \& Stone, G. O. (1996). Statistical analysis of the bidirectional inconsistency of spelling and sound in French. Behavior Research Methods, Instruments \& Computers, 28, 504-515.

Ziegler, J. C., Perry, C., \& Coltheart, M. (2000). The DRC model of visual word recognition and reading aloud: An extension to German. European Journal of Cognitive Psychology, 12, 413-430.

Ziegler, J. C., Perry, C., Ma-Wyatt, A., Ladner, D., \& Schulte-Korne, G. (2003a). Developmental dyslexia in different languages: Language-specific or universal? Journal of Experimental Child Psychology, 86, 169-193.

Ziegler, J. C., Perry, C., \& Coltheart, M. (2003b). Speed of lexical and nonlexical processing in French: The case of the regularity effect. Psychonomic Bulletin \& Review, 10, 947-953.

Ziegler, J. C., Stone, G. O., \& Jacobs, A. M. (1997). What is the pronunciation for -ough and the spelling for $/ \mathrm{u} /$ ? A data base for computing feedforward and feedback consistency in English. Behavior Research Methods Instruments and Computers, 29, 600-618. 
Appendix 1.

\section{APPENDICES}

Sample Size, Sex Ratio, Chronological Age (CAC) and Reading Level (RLC) Controls

English

$\underline{\text { French }}$

$\underline{\text { Spanish }}$

\begin{tabular}{|c|c|c|c|c|c|c|c|}
\hline & $\begin{array}{r}\text { Castles \& } \\
\text { Coltheart } \\
1993\end{array}$ & $\begin{array}{r}\text { Manis } \\
\text { et al. } \\
1996 \\
\end{array}$ & $\begin{array}{r}\text { Stanovich et } \\
\text { al. } \\
1997 \\
\end{array}$ & $\begin{array}{r}\text { Génard } \\
\text { et al. } \\
1998 \\
\end{array}$ & $\begin{array}{r}\text { Sprenger- } \\
\text { Charolles et al. } \\
2000\end{array}$ & $\begin{array}{r}\text { Ziegler } \\
\text { et al. } \\
2008 \\
\end{array}$ & $\begin{array}{r}\text { Jiménez } \\
\text { et al. } \\
2009 \\
\end{array}$ \\
\hline \multirow{4}{*}{$\begin{array}{l}\text { Number of Dyslexics } \\
\text { Sex Ratio (Male/Female) } \\
\text { Mean Chronological Age } \\
\text { Range (years or months) }\end{array}$} & 53 & 51 & 68 & 75 & 31 & 24 & 35 \\
\hline & $53-0$ & $37-14$ & $29-39$ & $50-25$ & $20-11$ & $15-9$ & $22-13$ \\
\hline & 11 & 12 & 9 & 10 & 10 & 10 & 10 \\
\hline & $81 / 2$ to $15 \mathrm{Y}-\mathrm{O}$ & 9 to $15 \mathrm{Y}-\mathrm{O}$ & 11 months & 9 to $12 \mathrm{Y}-\mathrm{O}$ & 11 months & 8 to $12 \mathrm{Y}-\mathrm{O}$ & $71 / 2$ to $11 Y-O$ \\
\hline \multirow{2}{*}{$\begin{array}{l}\text { Number of CAC } \\
\text { Sex Ratio (Male/Female) }\end{array}$} & 56 & 51 & 44 & 231 & 19 & 24 & 47 \\
\hline & $56-0$ & $35-16$ & $16-28$ & $99-132$ & $11-8$ & $12-12$ & $23-24$ \\
\hline \multirow[t]{2}{*}{$\begin{array}{l}\text { Number of RLC } \\
\text { Sex Ratio (Male/Female) }\end{array}$} & $17 *$ & 27 & 23 & 256 & 19 & No data & 40 \\
\hline & $17-0$ & $18-9$ & $13-10$ & $109-147$ & $11-8$ & & $20-20$ \\
\hline
\end{tabular}

*Analyses reported in Stanovich et al. (1997) including 40 of the 53 dyslexics 
Appendix 2.

Mean Percentage (and Number) of Different Dyslexic Profiles in Each Study for the Chronological-Age Comparison according to the Classical Method (2a) and to the Regression-Based Method (2b) and for the Reading Level Comparison (2c): Results based on Accuracy and Vocal Response Latency

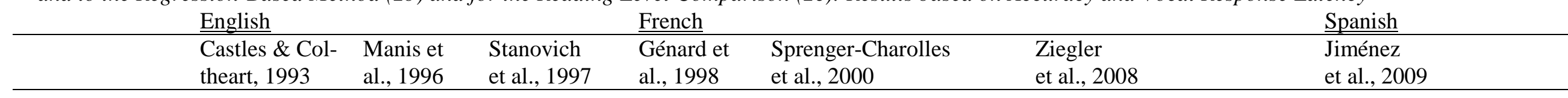

2a. Chronological-Age Comparison. Classical Method: Hard subtypes (Cut-off: 1 Standard-Deviation)

\begin{tabular}{|c|c|c|c|c|c|c|c|c|c|c|}
\hline & Accuracy $^{\mathrm{a}}$ & Accuracy & Accuracy $^{\mathrm{b}}$ & Accuracy & Accuracy & Latency & Accuracy $^{\mathrm{c}}$ & Latency $^{\mathrm{c}}$ & Accuracy ${ }^{\mathrm{d}}$ & Speed $^{\mathrm{d}}$ \\
\hline Phono. DYS & $15(08)$ & $10(05)$ & $9(06)$ & $3(02)$ & $10(03)$ & $16(05)$ & $8(02)$ & $17(04)$ & $8(03)$ & $11(04)$ \\
\hline Surface DYS & $17(09)$ & $10(05)$ & $12(08)$ & $23(17)$ & $19(06)$ & $19(06)$ & $21(05)$ & $21(05)$ & $23(08)$ & $14(05)$ \\
\hline Mixed Profiles & $60(32)$ & $76(39)$ & $75(51)$ & $67(50)$ & $68(21)$ & $52(16)$ & $46(11)$ & $42(10)$ & $43(15)$ & 54 (19) \\
\hline Without Deficit & $8(04)$ & $4(02)$ & $4(03)$ & $8(06)$ & $3(01)$ & $13(04)$ & $25(06)$ & $21(05)$ & $26(09)$ & $20(07)$ \\
\hline
\end{tabular}

2b. Chronological-Age Comparison. Regression-based Method: Soft subtypes (Confidence Interval [CI]: 90 or 95)

\begin{tabular}{|c|c|c|c|c|c|c|c|c|c|c|}
\hline $\mathrm{CI}$ & $\begin{array}{r}\text { Accuracy } \\
90\end{array}$ & $\begin{array}{r}\text { Accuracy } \\
95\end{array}$ & $\begin{array}{r}\text { Accuracy } \\
90\end{array}$ & $\begin{array}{r}\text { Accuracy } \\
95\end{array}$ & Accuracy $^{\mathrm{e}}$ & $\begin{array}{r}\text { Latency } \\
95\end{array}$ & $\begin{array}{r}\text { Accuracy } \\
95\end{array}$ & $\begin{array}{r}\text { Latency }^{c} \\
95\end{array}$ & $\begin{array}{r}\text { Accuracy } \\
90\end{array}$ & $\begin{array}{r}\text { Speed } \\
90\end{array}$ \\
\hline Phono. DYS & $55(29)$ & $33(17)$ & $25(17)$ & $4(03)$ & -- & $52(16)$ & $17(04)$ & $25(06)$ & $3(01)$ & $23(08)$ \\
\hline Surface DYS & $30(16)$ & $29(15)$ & $22(15)$ & $56(42)$ & -- & $32(10)$ & $29(07)$ & $46(11)$ & $3(01)$ & $46(16)$ \\
\hline Mixed Profiles & $6(03)$ & $10(05)$ & $28(19)$ & $3(02)$ & -- & $3(01)$ & $0(00)$ & $0(00)$ & $0(00)$ & $0(00)$ \\
\hline Without Deficit & $9(05)$ & $28(14)$ & $25(17)$ & $37(28)$ & -- & $13(04)$ & $54(13)$ & $29(07)$ & $94(33)$ & $31(11)$ \\
\hline
\end{tabular}

2c. Reading-Level Comparison. Regression-based Method: Soft subtypes (Confidence Interval [CI]: 90 or 95)

\begin{tabular}{|c|c|c|c|c|c|c|c|c|c|c|}
\hline CI & $\begin{array}{r}\text { Accuracy }^{\mathrm{f}} \\
90\end{array}$ & $\begin{array}{r}\text { Accuracy } \\
95\end{array}$ & $\begin{array}{r}\text { Accuracy } \\
90\end{array}$ & $\begin{array}{r}\text { Accuracy } \\
95\end{array}$ & Accuracy $^{\mathrm{e}}$ & $\begin{array}{r}\text { Latency } \\
95\end{array}$ & Accuracy $^{\mathrm{g}}$ & Latency $^{\mathrm{g}}$ & Accuracy $^{\mathrm{g}}$ & $\begin{array}{r}\text { Speed } \\
90\end{array}$ \\
\hline Phono. DYS & $37.5(15)$ & $29(15)$ & $25(17)$ & $8(06)$ & -- & $39(12)$ & -- & -- & -- & $34(12)$ \\
\hline Surface DYS & $5(02)$ & $2(01)$ & $1.5(01)$ & $0(00)$ & -- & $10(03)$ & -- & -- & -- & $14(05)$ \\
\hline Mixed Profiles & $0(00)$ & $0(00)$ & $0(00)$ & $0(00)$ & -- & $0(00)$ & -- & -- & -- & $0(00)$ \\
\hline Without Deficit & $57.5(23)$ & $69(35)$ & $73.5(50)$ & $92(69)$ & -- & $52(16)$ & -- & -- & -- & $52(12)$ \\
\hline
\end{tabular}

a. From Manis et al., 1996; b. Unpublished data provided by Stanovich; c. Unpublished data provided by Ziegler; d. Unpublished data provided by Jiménez

e. Results not reported because of ceiling effect in the CA controls for irregular words; f. From Stanovich et al. (1997); g. Data not available 